\title{
Review Article \\ Perinatal Health Statistics as the Basis for Perinatal Quality Assessment in Croatia
}

\author{
Urelija Rodin, ${ }^{1}$ Boris Filipovićc-Grčić, ${ }^{2}$ Josip Đelmiš, ${ }^{3}$ Tatjana Glivetić, ${ }^{4}$ Josip Juras, ${ }^{3}$ \\ Željka Mustapić, ${ }^{2}$ and Ruža Grizelj ${ }^{2}$ \\ ${ }^{1}$ School of Medicine, University of Zagreb, School of Public Health “A. Štampar”, Croatian Institute of Public Health, \\ Rockefellerova 4, 10000 Zagreb, Croatia \\ ${ }^{2}$ School of Medicine, University of Zagreb, Clinical Hospital Center Zagreb, Department of Pediatrics, Kišpatićeva 12, \\ 10000 Zagreb, Croatia \\ ${ }^{3}$ School of Medicine, University of Zagreb, Clinical Hospital Center Zagreb, Department of Obstetrics and Gynecology, \\ Petrova 13, 10000 Zagreb, Croatia \\ ${ }^{4}$ General Hospital Zabok, Trg Dragutina Domjanića 6, 49210 Zabok, Croatia
}

Correspondence should be addressed to Urelija Rodin; urelija.rodin@hzjz.hr

Received 5 June 2015; Revised 7 October 2015; Accepted 9 November 2015

Academic Editor: Malgorzata Bala

Copyright (C) 2015 Urelija Rodin et al. This is an open access article distributed under the Creative Commons Attribution License, which permits unrestricted use, distribution, and reproduction in any medium, provided the original work is properly cited.

\begin{abstract}
Context. Perinatal mortality indicators are considered the most important measures of perinatal outcome. The indicators reliability depends on births and deaths reporting and recording. Many publications focus on perinatal deaths underreporting and misclassification, disabling proper international comparisons. Objective. Description of perinatal health care quality assessment key indicators in Croatia. Methods. Retrospective review of reports from all maternities from 2001 to 2014. Results. According to reporting criteria for birth weight $\geq 500 \mathrm{~g}$, perinatal mortality (PNM) was reduced by $31 \%$, fetal mortality (FM) by $32 \%$, and early neonatal mortality (ENM) by $29 \%$. According to reporting criteria for $\geq 1000 \mathrm{~g}$, PNM was reduced by $43 \%$, FM by $36 \%$, and ENM by $54 \%$. PNM in $\geq 22$ weeks' (wks) gestational age (GA) was reduced by $28 \%$, FM by $30 \%$, and ENM by $26 \%$. The proportion of FM at 32-36 wks GA and at term was the highest between all GA subgroups, as opposed to ENM with the highest proportion in 22-27 wks GA. Through the period, the maternal mortality ratio varied from 2.4 to $14.3 / 100,000$ live births. The process indicators have been increased in number by more than half since 2001, the caesarean deliveries from 11.9\% in 2001 to $19.6 \%$ in 2014 . Conclusions. The comprehensive perinatal health monitoring represents the basis for the perinatal quality assessment.
\end{abstract}

Dedicated to the memory of Professor Ante Dražančić, our teacher and founder of Croatian Perinatology

\section{Introduction}

Perinatal health care, as well as the other areas of health care, requires the usage of useful indicators for quality assessment and evaluation, which will enable sustainable planning in accordance with limited resources. A weighted sum of all essential indicators, including fetal and maternal, short-term, and long-term outcomes, as well as maternal satisfaction and the impact on future pregnancies and deliveries, would represent the ideal measure of quality [1]. However, all recommended perinatal health indicators cannot be produced and gathered through routine national health statistics system. Some of the indicators are already available in the international databases but not presented by subgroups, which would make them more specific and sensitive perinatal health measurements. According to the World Health Organization (WHO) recommendations for international comparisons, the countries should calculate the perinatal indicators for 
total births, fetal and early neonatal deaths $\geq 1000 \mathrm{~g}$ birth weight (BW), or $\geq 28$ weeks' (wks) gestational age (GA). Moreover, the inclusion of fetuses and infants weighing 500$999 \mathrm{~g}$ or $22-27$ completed wks GA in national statistics is recommended by WHO because it improves the coverage of reporting according to criteria for international comparisons and enables better evaluation outcomes [2]. Also, on the European community's research agenda, there was a need for defining measures of maternal and child health care and outcomes for use in evaluating health care and public health programmes. As a part of the EU's Health Monitoring Programme, PERISTAT (Perinatal Statistics) project has been launched in 1999 [3]. The objective of the PERISTAT project is to establish a high quality, innovative, internationally recognized, and sustainable European perinatal health information system. This system's goal is to produce data and analysis on a regular basis for use by national, European, and international stakeholders who make decisions about the health and health care of pregnant women and newborns. PERISTAT scientific advisory committee defined the core perinatal indicators list in order to monitor the perinatal health more precisely. These indicators are sufficient for international comparisons, measuring fetal and infant health outcomes and key interventions implemented to prevent death and morbidity $[4,5]$.

The aim of this study was to analyze the key indicators for perinatal health care quality assessment in Croatia for the period 2001-2014.

The feasible perinatal indicators for Croatia's perinatal health care assessment were as follows:

(i) Perinatal outcome indicators: perinatal mortality (PNM), fetal mortality (FM), early neonatal mortality (ENM) by BW subgroups ( $\geq 500 \mathrm{~g}$ and $\geq 1000 \mathrm{~g}$ ) and GA subgroups ( $\geq 22$ wks and $\geq 28$ wks), and maternal mortality.

(ii) Process indicators: antenatal visits, ultrasound (US) examinations, and caesarean deliveries (CS).

\section{Material and Methods}

2.1. Croatian Population Characteristics. According to the 2011 Census, the Croatian Bureau of Statistics (CBS) data, the Croatian population amounted to approximately 4.3 million, with approximately 40,000 deliveries and 50,000 deaths per year with negative natural trend [6]. Sociodemographic characteristics of population by WHO's estimates indicated low birth rate $(9.3 / 1,000)$, low total fertility rate $(1.5 /$ per woman, 15-49 years old), moderate death rate $(12.0 / 1,000)$, and moderate life expectancy at birth for both sexes (76 years) [7]. Numerous sociodemographic characteristics of mothers remain unknown since CBS collects a limited data set of these data like permanent residence, marital status, parity, and professional birth attendance [6]. According to CBS data in the period $2000-2013$, more than $80 \%$ of births were from marriages and more than $99 \%$ in health institutions [8]. Almost half of all deliveries were first deliveries, $35 \%$ second, and $15 \%$ third or higher birth order. Concerning the mother age, the deliveries were most common at the age 25-29 (91.8 deliveries per 1,000 females of the same age), followed by the age 30-34 (89.7 deliveries per 1,000 females of this age), and at the age 20-24 (47.5/1,000). The overall average birth age was 30, while the average age at first birth among women was 27 years [6,9]. About 3\% were births from multiple pregnancies [9]. CBS vital statistics data about births are limited to sex, live birth (LB) or stillbirth, and residence. It was a basic reason for routine health statistics system improvement and introduction of new medical birth notification for birth monitoring with a broader set of data in 2001.

Despite efforts for better data entry in health institutions, the Croatian Institute of Public Health (CIPH) as the main producer of routine health statistics disposes of some basic data of newborns like sex, GA, and BW. According to CIPH data, 20,283 males and 19,505 females were born in the year 2014 and there was 1,04:1 male: female newborn ratio. In this period, there were $5.24 \%$ newborns with BW less than 2500 g: 0.51\% newborns with extremely low birth weight (less than $1000 \mathrm{~g}$ (ELBW) newborns), $0.47 \%$ newborns of BW $1000-1499 \mathrm{~g}, 1.08 \%$ newborns of BW $1500-1999 \mathrm{~g}$, and $3.18 \%$ newborns of BW 2000-2499 g [9].

During the war and the postwar period in Croatia, the share of preterm births amounted to $7-8 \%$ [10]; in the period 2001-2010, this share decreased to 5.8\% [11], while in the period 2010-2014, the increase was present up to $6.2 \%$ [12].

2.2. Study Design. The reports were retrieved from CIPH for the period 2001-2014, after collecting and processing birth, fetal deaths, and early neonatal deaths data from maternities and neonatal intensive care units (NICUs). These reports derived from hospital data were obtained as a part of the CIPH and Croatian Society of Perinatal Medicine (CSPM) Programme for perinatal health surveillance and reporting. According to these reports, there were 587,356 total births $\geq 22$ wks and 4,633 perinatal deaths $\geq 22$ wks (Table 1 ).

Perinatal data collecting according to the WHO recommendations by the BW and GA groups has been introduced in Croatian maternities since 2001 by the CIPH, in cooperation with CSPM, through two ways: reports with aggregated birth and perinatal death data by the BW and GA subgroups and individual birth and perinatal death notifications based on hospital discharges [10].

WHO encourages countries to build perinatal monitoring capacity and collect data for key perinatal mortality indicators, relying on the same definitions in order to allow for the comparison of these statistics. The events related to birth, death, and the perinatal period, as well as the reporting requirements for the data from which internationally comparable statistics are drawn, are defined in detail in the International Classification of Diseases, 10th Edition (ICD10), Instruction Manual, [2].

WHO recommended definition for national purposes [2]:

PNM

$=\frac{\text { Fetal deaths and early neonatal deaths } \geq 500 \mathrm{~g} \text { or } \geq 22 \mathrm{wks}}{}$ Total births $\geq 500 \mathrm{~g}$ or $\geq 22 \mathrm{wks}$

$\times 1000$, 
TABLE 1: Total births, fetal, early neonatal and perinatal deaths in Croatian maternities in the period 2001-2014.

\begin{tabular}{lcccc}
\hline Year & $\begin{array}{c}\text { Total births } \geq 22 \text { wks } \\
\text { numbers }\end{array}$ & $\begin{array}{c}\text { Fetal deaths } \geq 22 \text { wks } \\
\text { numbers }\end{array}$ & $\begin{array}{c}\text { Early neonatal deaths } \\
222 \text { wks numbers }\end{array}$ & $\begin{array}{c}\text { Perinatal deaths } \geq 22 \text { wks } \\
\text { numbers }\end{array}$ \\
\hline 2001 & 41,487 & 235 & 173 & 408 \\
2002 & 40,493 & 234 & 152 & 386 \\
2003 & 40,013 & 227 & 139 & 383 \\
2004 & 40,759 & 231 & 146 & 383 \\
2005 & 43,030 & 237 & 138 & 356 \\
2006 & 41,964 & 218 & 139 & 334 \\
2007 & 42,456 & 195 & 118 & 320 \\
2008 & 44,315 & 202 & 149 & 340 \\
2009 & 45,071 & 191 & 108 & 323 \\
2010 & 43,842 & 215 & 102 & 260 \\
2011 & 41,556 & 158 & 78 & 239 \\
2012 & 42,074 & 161 & 92 & 248 \\
2013 & 40,319 & 156 & 125 & 283 \\
2014 & 39,977 & 158 & & \\
\hline
\end{tabular}

$\mathrm{FM}=\frac{\text { Fetal deaths } \geq 500 \mathrm{~g} \text { or } \geq 22 \mathrm{wks}}{\text { Total births } \geq 500 \mathrm{~g} \text { or } \geq 22 \mathrm{wks}} \times 1000$,

ENM

$=\frac{\text { Early neonatal deaths or } \geq 500 \mathrm{~g} \text { or } \geq 22 \mathrm{wks}}{\mathrm{LB} \geq 500 \mathrm{~g} \text { or } \geq 22 \mathrm{wks}} \times 1000$.

WHO recommended definition for international comparison:

\section{PNM}

$$
\begin{aligned}
= & \frac{\text { Fetal deaths and early neonatal deaths } \geq 1000 \mathrm{~g} \text { or } \geq 28 \mathrm{wks}}{\text { Total births } \geq 1000 \mathrm{~g} \text { or } \geq 28 \mathrm{wks}} \\
& \times 1000,
\end{aligned}
$$$$
\mathrm{FM}=\frac{\text { Fetal deaths } \geq 1000 \mathrm{~g} \text { or } \geq 28 \mathrm{wks}}{\text { Total births } \geq 1000 \mathrm{~g} \text { or } \geq 28 \mathrm{wks}} \times 1000,
$$

ENM

$$
=\frac{\text { Early neonatal deaths or } \geq 1000 \mathrm{~g} \text { or } \geq 28 \mathrm{wks}}{\mathrm{LB} \geq 1000 \mathrm{~g} \text { or } \geq 28 \mathrm{wks}} \times 1000 \text {. }
$$

Following the year 2001, according to the new methodology, the calculations for PNM and FM based on reports from the maternities have been obtained according to the national and international reporting criteria [13]. However, for the purpose of obtaining the vital statistics, all dead LB, independently of BW or GA, have been included in infant mortality.

Maternal mortality data from medical death records in $\mathrm{CIPH}$ were matched with CBS vital statistics data. The record of each death during pregnancy, childbirth, and puerperium was verified together by experts from CIPH and CSPM in order to get complete and reliable data. The WHO defines maternal death as the death of a woman while pregnant or within 42 days of termination of pregnancy, irrespective of the duration and site of the pregnancy, of any cause related to or aggravated by the pregnancy or its management but not of accidental or incidental causes. This definition allows identification of maternal deaths based on their causes as either direct or indirect. The direct obstetric deaths are those resulting from obstetric complications of the pregnant state (pregnancy, delivery, and postpartum period), from interventions, omissions, or incorrect treatment, or from a chain of events resulting from any of the above. The indirect obstetric deaths are those resulting from previous existing disease or diseases that develop during pregnancy and which were not due to direct obstetric causes but were aggravated by physiological effects of pregnancy [14]. The WHO Conference agreed that since the number of LB was more universally available than the number of total births, it should be used as the denominator in the ratios related to maternal mortality $[2,14]$. Therefore, the maternal mortality ratio (MMR) in Croatia has been calculated including direct and indirect causes of woman death in pregnancy, delivery, or puerperium on 100,000 LB [13].

Data for process indicators (antenatal visits, US, and CS) have been obtained from maternities and CS proportions on 100 LB compared with WHO Health For All (WHO-HFA) database indicators.

\section{Results}

\subsection{Perinatal Outcome Indicators}

3.1.1. Perinatal, Fetal, and Early Neonatal Mortality by Birth Weight Subgroups ( $\geq 500 \mathrm{~g}$ and $\geq 1000 \mathrm{~g}$ ). In the period 20012014, PNM for all $\geq 500 \mathrm{~g}$ BW total births was reduced by $30.6 \%$, from $9.8 \%$ o to $6.8 \%$, FM for all $\geq 500 \mathrm{~g}$ by $32.1 \%$, from $5.6 \%$ o to $3.8 \%$, and ENM by $28.6 \%$, from $4.2 \%$ o to $3.0 \%$. In the same period of time, PNM for all $\geq 1000 \mathrm{~g}$ BW total births was reduced by $42.5 \%$ (from $7.3 \%$ in 2001 to $4.2 \%$ in 2014 ). 
TABLE 2: Perinatal, fetal, and early neonatal mortality rates (\%o) in total births' birth weight $\geq 500 \mathrm{~g}$ and birth weight $\geq 1000 \mathrm{~g}$ in Croatia in the period 2001-2014.

\begin{tabular}{|c|c|c|c|c|c|c|}
\hline Year & $\mathrm{PNM} \geq 500 \mathrm{~g}(\%)$ & $\mathrm{PNM} \geq 1000 \mathrm{~g}(\% \mathrm{o})$ & $\mathrm{FM} \geq 500 \mathrm{~g}(\% \mathrm{o})$ & $\mathrm{FM} \geq 1000 \mathrm{~g}(\% \mathrm{o})$ & $\mathrm{ENM} \geq 500 \mathrm{~g}(\% \mathrm{o})$ & $\mathrm{ENM} \geq 1000 \mathrm{~g}(\%)$ \\
\hline 2001 & 9.8 & 7.3 & 5.6 & 4.5 & 4.2 & 2.8 \\
\hline 2002 & 9.3 & 6.9 & 5.6 & 4.3 & 3.7 & 2.6 \\
\hline 2003 & 9.5 & 6.3 & 5.7 & 4.1 & 3.8 & 2.2 \\
\hline 2004 & 8.7 & 5.8 & 5.3 & 3.9 & 3.4 & 1.9 \\
\hline 2005 & 8.8 & 6.4 & 5.4 & 4.2 & 3.4 & 2.2 \\
\hline 2006 & 8.3 & 5.3 & 5.1 & 3.4 & 3.2 & 1.9 \\
\hline 2007 & 7.8 & 4.9 & 4.5 & 3.1 & 3.2 & 1.8 \\
\hline 2008 & 7.0 & 4.6 & 4.4 & 3.2 & 2.6 & 1.4 \\
\hline 2009 & 7.2 & 4.4 & 4.2 & 3.0 & 3.0 & 1.5 \\
\hline 2010 & 7.2 & 4.7 & 4.8 & 3.5 & 2.4 & 1.2 \\
\hline 2011 & 5.9 & 3.5 & 3.6 & 2.5 & 2.3 & 1.0 \\
\hline 2012 & 5.4 & 3.6 & 3.6 & 2.7 & 1.7 & 0.9 \\
\hline 2013 & 5.8 & 3.5 & 3.6 & 2.5 & 2.2 & 1.0 \\
\hline 2014 & 6.8 & 4.2 & 3.8 & 2.9 & 3.0 & 1.3 \\
\hline
\end{tabular}

TABLE 3: Perinatal, fetal, and early neonatal mortality rates (\%o) in gestational age subgroups $\geq 22$ weeks and $\geq 28$ weeks in Croatia in the period 2001-2014.

\begin{tabular}{|c|c|c|c|c|c|c|}
\hline Year & $\mathrm{PNM} \geq 22$ wks (\%o) & $\mathrm{PNM} \geq 28$ wks $(\% 0)$ & $\mathrm{FM} \geq 22$ wks (\%o) & $\mathrm{FM} \geq 28$ wks $(\% 0)$ & $\mathrm{ENM} \geq 22$ wks (\%o) & $\mathrm{ENM} \geq 28$ wks $(\% 0)$ \\
\hline 2001 & 9.8 & 7.4 & 5.7 & 4.7 & 4.2 & 2.7 \\
\hline 2002 & 9.5 & 7.4 & 5.8 & 4.8 & 3.8 & 2.6 \\
\hline 2003 & 9.6 & 6.6 & 5.7 & 4.4 & 3.9 & 2.1 \\
\hline 2004 & 9.1 & 6.3 & 5.7 & 4.4 & 3.4 & 1.9 \\
\hline 2005 & 8.9 & 6.7 & 5.5 & 4.5 & 3.4 & 2.2 \\
\hline 2006 & 8.5 & 5.8 & 5.2 & 4.0 & 3.3 & 1.8 \\
\hline 2007 & 7.9 & 5.5 & 4.6 & 3.6 & 3.3 & 1.9 \\
\hline 2008 & 7.2 & 4.8 & 4.6 & 3.5 & 2.7 & 1.3 \\
\hline 2009 & 7.5 & 4.7 & 4.2 & 3.2 & 3.3 & 1.5 \\
\hline 2010 & 7.4 & 5.0 & 4.9 & 3.8 & 2.5 & 1.2 \\
\hline 2011 & 6.3 & 3.8 & 3.8 & 2.9 & 2.5 & 0.9 \\
\hline 2012 & 5.7 & 3.9 & 3.8 & 3.0 & 1.9 & 0.9 \\
\hline 2013 & 6.2 & 3.9 & 3.9 & 2.9 & 2.3 & 1.0 \\
\hline 2014 & 7.1 & 4.4 & 4.0 & 3.0 & 3.1 & 1.5 \\
\hline
\end{tabular}

The FM was reduced by $35.6 \%$ (from $4.5 \%$ to $2.9 \%$ ) and ENM by more than half (53.6\%, from $2.8 \%$ o to $1.3 \%$ ), with slight variations in the rates over the years (Table 2).

3.1.2. Perinatal, Fetal, and Early Neonatal Mortality by Gestational Age Subgroups ( $\geq 22 w k s$ and $\geq 28 w k s)$. In the period 2001-2014, PNM in all $\geq 22$ wks GA group was reduced by about one-quarter $(27.6 \%$, from $9.8 \%$ in 2001 to $7.1 \%$ o in 2014). FM was reduced by $29.8 \%$ (from $5.7 \%$ o to $4.0 \%$ ) and ENM by $26.2 \%$ (from $4.2 \%$ to $3.1 \%$ ). In the same period of time, PNM in all $\geq 28$ wks GA was reduced by $40.6 \%$ (from $7.4 \%$ o to $4.4 \%$ ), FM in all $\geq 28$ wks GA by $36.1 \%$ (from $4.7 \%$ o to $3.0 \%$ ), and ENM by $44.6 \%$ (from $2.7 \%$ o to $1.5 \%$ ) (Table 3 ).

Figure 1 reports FM attributable to each of the four GA groups: $22-27 ; 28-31 ; 32-36$; and $\geq 37$ wks. This figure illustrates the impact of FM subgroup differences on overall rates. FM ranged from $1.2 \%$ to $1.8 \%$ in $32-36$ wks GA subgroup and from $0.9 \%$ o to $2.2 \%$ in $37-41$ wks GA subgroup, for both subgroups more than a half of overall FM throughout the period 2001-2014.

ENM was the highest in 22-27 wks GA subgroup, representing more than one-third to more than a half of the total of all early neonatal deaths in the period 2001-2014. ENM ranged from $1.0 \%$ o to $1.8 \%$ in this GA (Figure 2 ).

3.2. Maternal Mortality. Table 4 reports MMR related to the direct and indirect obstetric causes for the period 2001-2014. Total MMR varied from 2.4 to $14.3 / 100,000 \mathrm{LB}$. In the period 2010-2014, the decreasing trend in direct obstetrical causes could be observed. In the period 2001-2014, the direct obstetric deaths due to pregnancy, labor, or puerperium caused $63.8 \%$ of all maternal deaths. The indirect obstetric deaths due to maternal chronic diseases, malignant diseases, and other 
TABLE 4: Maternal deaths and maternal mortality ratios related to the direct and indirect obstetric causes/100,000 live births.

\begin{tabular}{|c|c|c|c|c|c|c|}
\hline \multirow{2}{*}{ Year } & \multicolumn{2}{|c|}{ MD: all causes } & \multicolumn{2}{|c|}{ MD: direct obstetric causes } & \multicolumn{2}{|c|}{ MD: indirect obstetric causes } \\
\hline & Numbers & MMR & Numbers & MMR & Numbers & MMR \\
\hline 2001 & 1 & 2.4 & 1 & 2.4 & 0 & 0 \\
\hline 2002 & 4 & 10.0 & 4 & 10.0 & 0 & 0 \\
\hline 2003 & 3 & 7.6 & 3 & 7.6 & 0 & 0 \\
\hline 2004 & 3 & 7.4 & 2 & 5.0 & 1 & 2.5 \\
\hline 2005 & 3 & 7.1 & 1 & 2.4 & 2 & 4.7 \\
\hline 2006 & 4 & 9.7 & 2 & 4.8 & 2 & 4.8 \\
\hline 2007 & 6 & 14.3 & 3 & 7.2 & 3 & 7.2 \\
\hline 2008 & 3 & 6.9 & 1 & 2.3 & 2 & 4.6 \\
\hline 2009 & 6 & 13.5 & 6 & 13.5 & 0 & 0 \\
\hline 2010 & 4 & 9.2 & 1 & 2.3 & 3 & 6.9 \\
\hline 2011 & 4 & 9.7 & 3 & 7.3 & 1 & 2.4 \\
\hline 2012 & 3 & 7.2 & 1 & 2.4 & 2 & 4.8 \\
\hline 2013 & 2 & 5.0 & 1 & 2.5 & 1 & 2.5 \\
\hline 2014 & 1 & 2.5 & 1 & 2.5 & 0 & 0 \\
\hline 2001-2014 & 47 & 8.1 & 30 & 5.2 & 17 & 2.9 \\
\hline
\end{tabular}

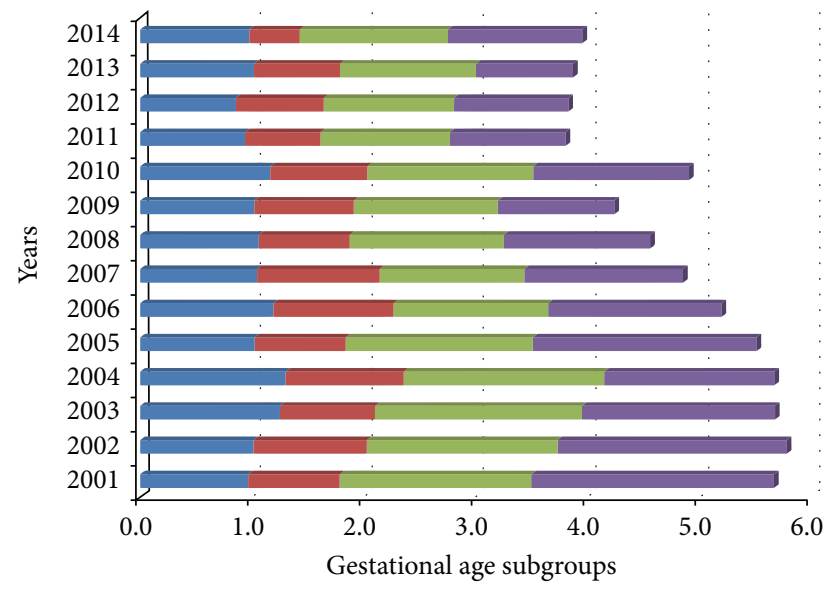

22-27 weeks

28-31 weeks

32-36 weeks

$\geq 37$ weeks

FIGURE 1: Fetal mortality attributed to gestational age subgroup (per 1,000 total births).

causes unrelated to pregnancy, labor, or puerperium caused the remaining $36.2 \%$ of all maternal deaths.

\subsection{Perinatal Process Indicators}

3.3.1. Antenatal Visits and Ultrasound Examinations. Figure 3 reports the proportion of pregnant women with $0-2,3-5,6-$ 8 , and $\geq 9$ antenatal visits. The percentage of pregnant women with $\geq 9$ visits increased from $43.0 \%$ in 2001 to $72.3 \%$ in 2014 , followed by other subgroups' proportion decrease.

Figure 4 reports the proportion of pregnant women with $0,1,2,3$, and $\geq 4$ US in pregnancy. The percentage of pregnant

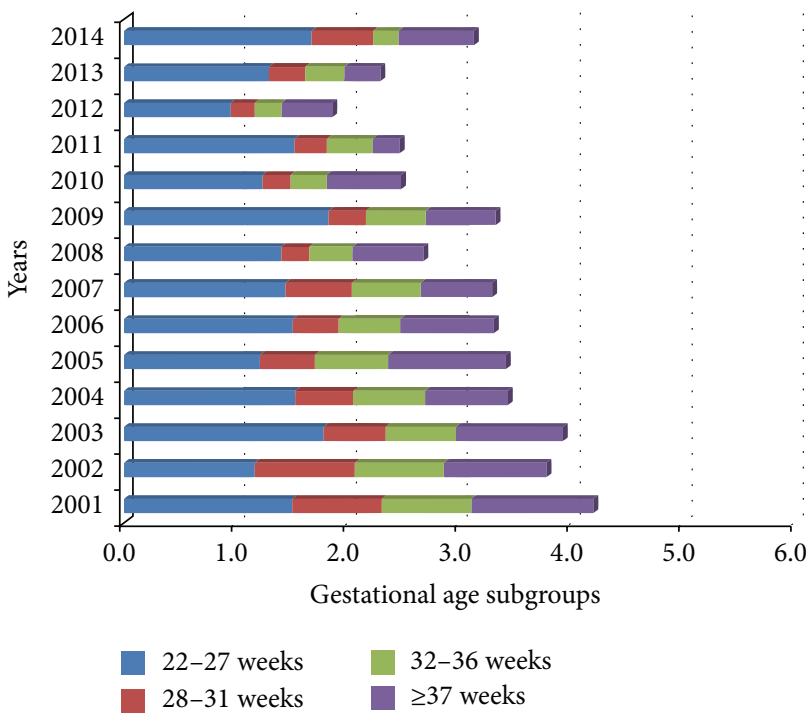

FIGURE 2: Early neonatal mortality attributed to gestational age subgroup (per 1,000 live births).

women with $\geq 4$ visits increased from $63.1 \%$ in 2001 to $93.4 \%$ in 2014, followed by other subgroups' proportion decrease.

3.3.2. Caesarean Section. The frequency of CS is continuously rising. Figure 5 reports the comparison with EU average.

\section{Discussion}

The key indicators for perinatal health care quality assessment in Croatia were analyzed after introducing new reporting criteria in routine health statistics on national level for monitoring PNM, FM, and ENM in 2001. The changes in 


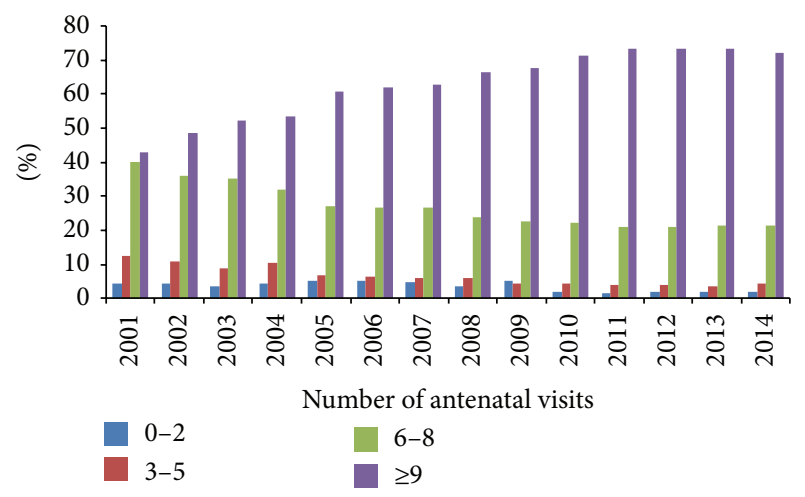

FIGURE 3: Distribution of pregnant women in relation to antenatal visits in the period 2001-2014.

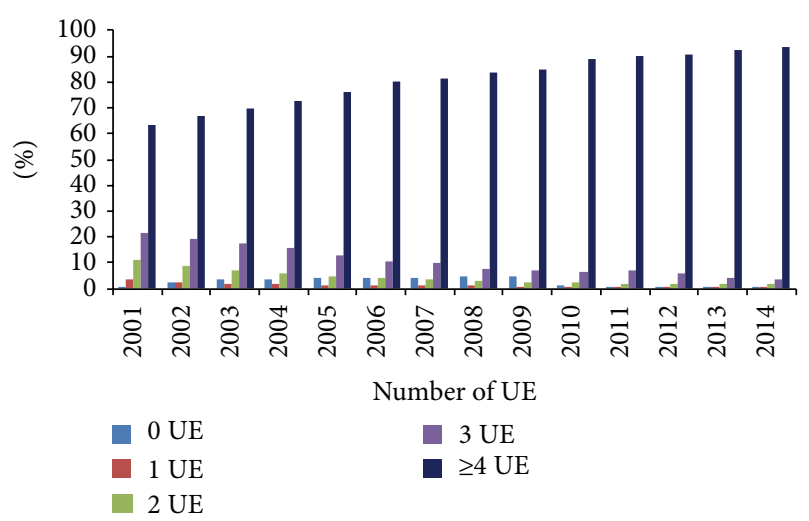

Figure 4: Distribution of pregnant women by ultrasound examination frequency in the period 2001-2014.

reporting criteria have enabled us to have a deeper insight into PNM, FM, and ENM trends in births $<1000 \mathrm{~g} \mathrm{BW}$ and $<28$ completed wks GA. According to reporting criteria for international comparisons and WHO-HFA indicators, PNM and FM in Croatia were below EU average [15]. However, this study showed that the inclusion of perinatal deaths $<1000 \mathrm{~g}$ BW and $<28$ completed wks GA considerably changes picture about perinatal outcomes in Croatia. Furthermore, the study showed that the highest ENM was in 22-27 wks GA, by more than third to more than a half of the total ENM in the period 2001-2014, which is reflected in the increase in total PNM, in particular in 2013-2014.

Another important finding of this study was that, according to antenatal visits and US examinations which are prenatal care measures, the highest number of mothers was included in the optimal number of examinations in accordance with national recommendations [16]. This implies that some other factors like perinatal health care organization could have influenced ENM and PNM trends in 22-27 wks GA in Croatia and should be additionally investigated.

The mortality indicators are considered the most important measures of perinatal outcome, encouraging the health care professional efforts to prevent avoidable deaths. The data reliability depends on credible reporting and births and deaths recording process. The numerous researches

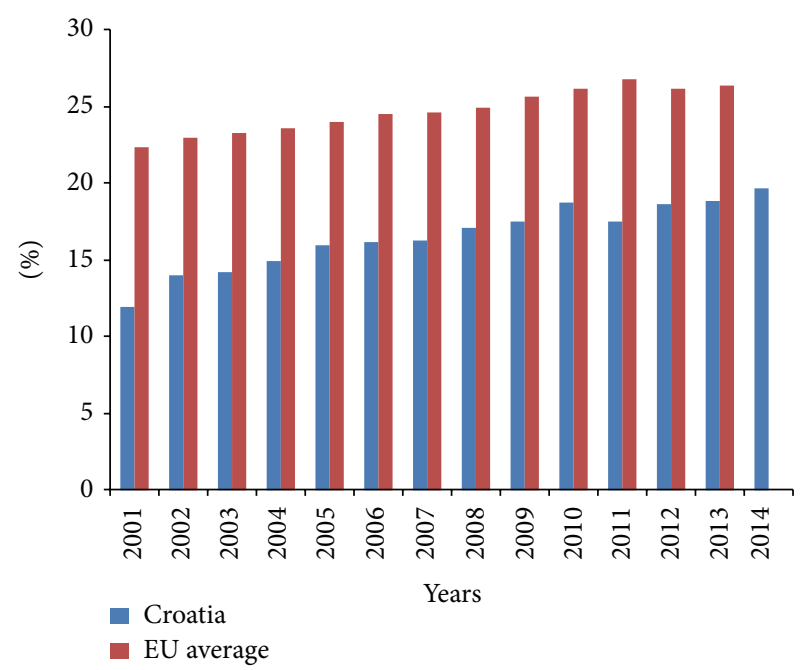

FIGURE 5: The proportion of caesarean sections in Croatia and EU average per 100 live births in the period 2001-2014.

have been emphasizing the problem of stillbirths and early neonatal deaths underreporting and misclassification [1727]. The civil registration systems from many countries provide only basic information related to numbers of births and deaths and registration is required by law. However, the majority of civil registers do not collect birth or perinatal death data according to BW or GA. As in majority of countries, the main source of perinatal mortality indicators in Croatia was civil registration system, which was based on the birth and death certificates from CBS. According to the CBS methodology, FM is calculated as a number of stillbirths after 28th completed wks of pregnancy on 1,000 total births, irrespective of GA, up to the year 2001. ENM is calculated as a number of newborns who died in the first 168 hours (7 days) of life on 1,000 LB, irrespective of BW or GA. Whereas CBS does not collect data according to WHO and PERISTAT recommendations, it was impossible to carry out precise perinatal monitoring and international comparisons. Therefore, CSPM and CIPH introduced perinatal monitoring according to reports from maternities and developed new medical birth and perinatal death certificates by BW and GA, implementing their usage in the national routine health statistics system which covers more than $99 \%$ of births and perinatal deaths. However, the new monitoring system based on individual records needed a few years for developing and improving $[13,17]$. Since 2001, Croatia has been providing the data about all perinatal deaths $\geq 1000 \mathrm{~g}$ to WHO-HFA for PNM calculations according to criteria for international comparison. For the purpose of the national analyses and evaluation of perinatal health care, both rates (according to $\mathrm{BW} \geq 500 \mathrm{~g}$ and $\geq 1000 \mathrm{~g}$ ) are used.

A similar reporting problem was detected in many European countries, preventing the perinatal, neonatal, postneonatal, and infant mortality comparisons by the BW or GA subgroups per country [22]. The health statistics systems differ in data collection methodology and area of coverage. Many countries use some form of linkage procedure to merge 
data from different sources. In international databases such as WHO-HFA and the Statistical Office of the European Communities (Eurostat) database, these indicators can be found to be related to the different methodologies: for WHOHFA database countries, the perinatal mortality indicator for BW group $\geq 1000$ g or group $\geq 28$ wks of GA is provided, while for Eurostat, it is according to different national statistical offices data for vital statistics registration. These data are not sufficient for perinatal outcome measures as opposed to the PERISTAT subgroup and GA division due to the fact that more than $70 \%$ of perinatal deaths in developed countries are connected with preterm birth and low BW [17$19,21,22,28]$. The lack of BW and GA data for late neonatal and postneonatal deaths hinders the analyses of the longterm consequences caused by ELBW and/or GA: physical, neurological, and cognitive impairments.

PNM, FM, and ENM by BW and GA have been regularly analyzed and discussed at annual national perinatal mortality conferences as a form of perinatal surveillance with the basic aim of preventing unfavorable perinatal outcomes [10]. Croatian PNM, calculated by WHO-HFA methodology criteria of $\mathrm{BW} \geq 1000 \mathrm{~g}$, seems to be lower than European Union (EU) average, amounting to below $5 \%$ o for the period of 2007 onwards [15]. FM rates were $5.7 \%$ - $4.0 \%$ o for $\geq 22 \mathrm{wks}$ in the period 2001-2014, mildly decreasing from 2001 to 2014. In comparison with the PERISTAT survey data for 2010, the European countries range from $2.6 \%$ to $8.9 \%$ [29]. The first Croatian data originated in the year 1950, indicating FM rate of $17.8 \%$, which gradually decreased to today's value [10]. ENM rates were $4.4-3.1 \%$ for $\geq 22$ wks in the period $2001-$ 2014, decreasing in 2012 and increasing in the years 2013 and 2014. In comparison with the PERISTAT survey data for 2010, the European countries range from $1.0 \%$ o to $4.0 \%$, but mostly in the scope from $1.5 \%$ to $2.0 \%$ [29]. The first officially published ENM rate in Croatia was $27.7 \%$ o in the year 1950 with substantial decrease, especially after 1996 when FM rate was surpassed [10]. The perinatal health in Croatia, measured by PNM, FM, and ENM, has improved considerably in recent decades with the evident increase in ENM during the last two years, especially in 22-27 GA subgroup, which represents the cause for concern and requires detailed new analyses. According to other national studies, the increased number of ELBW newborns, mostly from multiple pregnancies, led to the rise of ENM resulting with the consequent rise of PNM over the last two years [12, 30-32].

The increase in the number of $<1500 \mathrm{~g} \mathrm{BW}$ newborns, LB, and deaths directs the perinatal health care endeavor towards the prevention, early diagnosis, and appropriate treatment of threatened early preterm labors, harmless delivery of those children, and thereafter appropriate treatment of those newborns in the NICUs $[10,23]$. This may be achieved by implementing a regional organization of perinatal health care according to evidence-based studies and observations [33-43]. The routine perinatal health monitoring system is an important tool which enables the health care planning process in accordance with the requirements for appropriate level of health care, including human resources and adequate equipment. In order to improve the structure of Croatian perinatal health care system, all maternities and neonatal units are organized in a network, regionalized according to the professional guidelines [44]. However, the network is not officially confirmed by the Ministry of Health of the Republic of Croatia. The pregnant women are referred, as well as postpartum sick newborns, to the facilities of appropriate level, according to maternal/infant health condition. The referrals are mainly towards the maternities with NICUs, level III, situated in own perinatal region. The most complicated pregnancies and newborns can be referred to the National Center of Perinatal Medicine or to the National Center of Neonatal Intensive Medicine (level IV). The transfer of the sick newborns is organized as "one-way transport" [44].

The pregnancy and childbirth still involve risk for pregnant women and their babies and health in the perinatal period, while remaining an important public health priority. Although poor outcomes are increasingly rare, mothers in Europe still die in childbirth (5-15 women per 100,000 LB) [45]. Not only does MMR represent a key perinatal health outcome, but also it indicates the quality of obstetrical care, since many direct maternal deaths are associated with substandard care. The analysis of maternal deaths revealed that one-third of them are avoidable. The indicators of maternal mortality are extremely sensitive to underreporting, both in developing and in developed countries [46, 47]. The ascertainment of maternal deaths requires an effort by governments to ensure that deaths during or within one year after pregnancy are identified on death certificates or using other measures. Their precise registration depends on cause of death coding rules.

MMR for Croatia displays the substantial variation over time and the average is $8.1 / 100,000 \mathrm{LB}$ during the period of 14 years, slightly higher than EU average considering the last few years. In 1954 (first known data), maternal mortality was $168 / 100,000$ LB, rapidly decreased in the period 1960-1980, afterwards showing the values below 10/100,000 LB [48]. Following the introduction of the new reporting criteria and registration in the year 2001, the death causes of women in pregnancy, labor, and 42 days after labor are double-checked by CIPH and CSPM. The increase of the overall maternal deaths might have been caused by the fact that CIPH and CSPM have been including the indirect causes of maternal death as a part of the overall maternal deaths count since 2001 . Up to the year 2001, Croatia reported only direct obstetrical maternal deaths.

The number of clinical visits and of US examinations of pregnant women is continuously increasing. The recommendations of CSPM, officially adopted and completely financed by Croatian Institute of Health Insurance, are 10 clinical visits per healthy pregnant woman and 3 US examinations [44]. The low proportion of pregnant women without adequate antenatal care and ultrasound examinations represents the indicators of prenatal care availability quality.

In view of the ongoing debates about the safest path to delivery, there is not yet clear consensus achieved. The spontaneous deliveries represented the majority of births in all countries, but the proportion of CS has been increased in the majority of European countries [15]. The rise of CS in Croatia, in comparison to the majority of European and other countries, is relatively mild. In relation to USA 
and some European countries, there is a certain lag period present $[49,50]$. There is an endeavor to stop further CS rise. The measurements of differences in mode of delivery under different circumstances including breech presentation, previous CS, parity, and multiple gestation pregnancies would offer better insight into necessity, risks, and benefits in specific circumstances.

The strength of this study is the perinatal mortality audit based on national routine health statistics which enables calculation of PNM, FM, and ENM rates adjusted for GA and BW for the whole population. The results can be considered as fairly reliable and representative for the entire country. Our review of perinatal mortality outcomes related to BW and GA specific mortality rates over the period of 14 years and comparisons with PERISTAT 2010 report can be considered a way to improve the health care process for all pregnant women and their newborns. It provides an opportunity to learn from adverse events, identifying and analyzing them and providing the future preventive measures.

The limitations of this study include the lack of the other perinatal health care indicators required for detailed insight into the provided perinatal health care, as well as perinatal morbidity outcomes with long-term physical, neurological, and cognitive impairment.

\section{Conclusions}

The perinatal health audit in Croatia has been improved after introducing recommended reporting criteria by WHO and PERISTAT which enable comparison in perinatal outcome with other countries. The outcome of this research provides an opportunity to identify problems and to prepare the plan for perinatal health care improvement. The perinatal monitoring system should be further improved while analyzing other perinatal indicators, except for the presented few core outcomes and process indicators, in order to achieve more complete image of perinatal care effectiveness and availability. The comprehensive perinatal health monitoring represents the basis for the perinatal quality assessment.

\section{Conflict of Interests}

The authors declare that there is no conflict of interests regarding the publication of this paper.

\section{Acknowledgments}

The authors thank all perinatologists and neonatologists in Croatia for their participation in data delivery.

\section{References}

[1] G. Lindmark and J. Langhoff-Ros, "Perinatal quality indicators and perinatal audit," in Textbook of Perinatal Medicine, A. Kurjak and F. A. Chervenak, Eds., vol. 1, pp. 264-268, 2nd edition, 2006.

[2] World Health Organization, "Standards and reporting requirements related to fetal, perinatal, neonatal and infant mortality," in International Statistical Classification of Diseases and
Related Health Problems. 10th Revision, vol. 2 of Instruction Manuel, chapter 5, pp. 151-156, World Health Organization, Valletta, Malta, 2011, http://www.who.int/classifications/icd/ ICD10Volume2_en_2010.pdf.

[3] J. Zeitlin, K. Wildman, G. Bréart et al., "PERISTAT. Indicators for monitoring and evaluating perinatal health in Europe," European Journal of Public Health, vol. 13, supplement 3, pp. 2937, 2003.

[4] J. Zeitlin, K. Wildman, and G. Bréart, "Perinatal health indicators for Europe: an introduction to the PERISTAT project," European Journal of Obstetrics Gynecology and Reproductive Biology, vol. 111, supplement 1, pp. S1-S4, 2003.

[5] J.Zeitlin, K. Wildman, G. Bréart et al., "Selecting an indicator set for monitoring and evaluating perinatal health in Europe: criteria, methods and results from the PERISTAT project," European Journal of Obstetrics Gynecology \& Reproductive Biology, vol. 111, supplement 1, pp. S5-S14, 2003.

[6] L. Ostroški, "Statistical Yearbook of the Republic of Croatia 2014," Croatian Bureau of Statistics, Zagreb, Croatia, 2014, http:// www.dzs.hr/Hrv_Eng/ljetopis/2014/sljh2014.pdf.

[7] World Health Organization, Croatia: WHO Statistical Profile, World Health Organization, Geneva, Switzerland, 2015, http:// www.who.int/gho/countries/hrv.pdf?ua=1.

[8] M. Pekeč and V. Petrić, "Is there a change occurring in Croatia in the 21 st century?" in Eurostat. Statistics Explained. Marriages and Births in Croatia, 2015, http://ec.europa.eu/eurostat/ statistics-explained/index.php/Marriages_and_births_in_Croatia/2015.

[9] T. Poljičanin and T. Benjak, "Croatian Health Service Yearbook 2014," Croatian Institute of Public Health, 2015, http://www.hzjz .hr/wp-content/uploads/2015/10/ljetopis_20142.pdf.

[10] A. Dražančić, U. Rodin, and B. Filipović-Grčić, "Perinatal care in Croatia yesterday, today, tomorrow," Liječnički Vjesnik, vol. 129, no. 3-4, pp. 87-99, 2007.

[11] U. Rodin, B. Filipović-Grčić, and A. Dražančić, "Births and perinatal mortality of very low birth weight newborns in Croatia in the 2001-2010 period," Gynaecologia et Perinatologia, vol. 20, supplement 2, pp. 46-50, 2011.

[12] J. Đelmiš, J. Juras, and U. Rodin, "Perinatal mortality in Republic of Croatia in the year 2014," Gynaecologia et Perinatologia, vol. 24, no. 1, pp. 3-18, 2015.

[13] U. Rodin, "Quality of data from new birth notification in Croatian maternities," Gynaecologia et Perinatologia, vol. 11, supplement 1, pp. 25-29, 2002.

[14] World Health Organization, Reviewing Maternal Deaths and Complication to Make Pregnancy Safer; Beyond the Numbers, Department of Reproductive Health and Research, World Health Organization, Geneva, Switzerland, 2004.

[15] World Health Organization, Health for All Database, World Health Organization, 2014, http://data.euro.who.int/hfadb.

[16] Ministry of Health, "Plan and Programme of Health Care Measures in Compulsory Health Insurance," Official Gazette, $126 / 2006$.

[17] J. B. Gould, "Vital records for quality improvement," Pediatrics, vol. 103, no. 1, supplement E, pp. 278-290, 1999.

[18] T. A. Slagle, "Perinatal information systems for quality improvement: visions for today," Pediatrics, vol. 103, no. 1, supplement E, pp. 266-277, 1999.

[19] M. S. Kramer, S. Liu, Z. Luo, H. Yuan, R. W. Platt, and K. S. Joseph, "Analysis of perinatal mortality and its components: time for a change?" American Journal of Epidemiology, vol. 156, no. 6, pp. 493-497, 2002. 
[20] P. H. T. Cartlidge and J. H. Stewart, "Effect of changing the stillbirth definition on evaluation of perinatal mortality rates," The Lancet, vol. 346, no. 8973, pp. 486-488, 1995.

[21] P. W. Setel, S. B. Macfarlane, S. Szreter et al., "A scandal of invisibility: making everyone count by counting everyone," The Lancet, vol. 370, no. 9598, pp. 1569-1577, 2007.

[22] A. Macfarlane, M. Gissler, F. Bloomer, and S. Rasmussen, "The availability of perinatal health indicators in Europe," European Journal of Obstetrics \& Gynecology and Reproductive Biology, vol. 111, supplement 1, pp. 15-32, 2003.

[23] J. E. Lawn, S. Cousens, and J. Zupan, “4 million neonatal deaths: when? Where? Why?” The Lancet, vol. 365, no. 9462, pp. 891900, 2005.

[24] N. Lack, J. Zeitlin, L. Krebs, W. Künzel, and S. Alexander, "Methodological difficulties in the comparison of indicators of perinatal health across Europe," European Journal of Obstetrics Gynecology and Reproductive Biology, vol. 111, supplement 1, pp. S33-S44, 2003.

[25] G. L. Darmstadt, Z. A. Bhutta, S. Cousens, T. Adam, N. Walker, and L. De Bernis, "Evidence-based, cost-effective interventions: how many newborn babies can we save?" The Lancet, vol. 365, no. 9463, pp. 977-988, 2005.

[26] K. Shibuya, S. Scheele, and T. Boerma, "Health statistics: time to get serious," Bulletin of the World Health Organization, vol. 83, no. 10, p. 722, 2005.

[27] J. E. Lawn, D. Osrin, A. Adler, and S. Cousens, "Four million neonatal deaths: counting and attribution of cause of death," Paediatric and Perinatal Epidemiology, vol. 22, no. 5, pp. 410416, 2008.

[28] S. Buitendijk, J. Zeitlin, M. Cuttini, J. Langhoff-Roos, and J. Bottu, "Indicators of fetal and infant health outcomes," European Journal of Obstetrics Gynecology and Reproductive Biology, vol. 111, supplement 1, pp. S66-S77, 2003.

[29] J. Zeitlin, A. Mohangoo, and M. Delnord, "The European Perinatal Health Report," 2010, http://www.europeristat.com/ reports/european-perinatal-health-report-2010.html.

[30] J. Đelmiš, J. Juras, and U. Rodin, "Perinatal mortality in Republic of Croatia in the year 2013," Gynaecologia et Perinatologia, vol. 23, no. 1, pp. S3-S18, 2014.

[31] U. Rodin, B. Filipović-Grčić, T. Ćorić, and J. Juras, "Perinatal deaths causes in Croatia in the year 2014," Gynaecologia et Perinatologia, vol. 24, no. 1, pp. 19-25, 2015.

[32] B. Filipović-Grčić, Ž. Mustapić, U. Rodin, D. Bartoniček, and R. Grizelj, "Mortality of newbornsto discharge from hospital in Croatia in the year 2014," Gynaecologia et Perinatologia, vol. 24, no. 1, pp. 26-32, 2015.

[33] E. Papiernik and L. G. Keith, "The regionalization of perinatal care in France-description of a missing policy," European Journal of Obstetrics and Gynecology, vol. 61, no. 2, pp. 99-103, 1995.

[34] R. Vieux, J. Fresson, J.-M. Hascoet et al., "Improving perinatal regionalization by predicting neonatal intensive care requirements of preterm infants: an EPIPAGE-based cohort study," Pediatrics, vol. 118, no. 1, pp. 84-90, 2006.

[35] K. Beeckman, F. Louckx, S. Downe, and K. Putman, "The relationship between antenatal care and preterm birth: the importance of content of care," European Journal of Public Health, vol. 23, no. 3, pp. 366-371, 2013.

[36] Committee on Perinatal Health, Toward Improving the Outcome of Pregnancy. Recommendations for the Regional Development of Maternal and Perinatal Health Services, The National Foundation-March of Dimes, White Plains, NY, USA, 1976.
[37] P. R. Swyer, "The regional organisation of special care for the neonate," Pediatric Clinics of North America, vol. 17, no. 4, pp. 761-776, 1970.

[38] K. P. Russell, S. H. Gardiner, and E. E. Nichols, "A conceptual model for regionalization and consolidation of obstetric-gynecologic services," American Journal of Obstetrics and Gynecology, vol. 121, no. 6, pp. 756-764, 1975.

[39] R. Usher, "Changing mortality rates with perinatal intensive care and regionalization," Seminars in Perinatology, vol. 1, no. 3, pp. 309-319, 1977.

[40] J. Zeitlin, E. Papiernik, and G. Bréart, "Regionalization of perinatal care in Europe," Seminars in Neonatology, vol. 9, no. 2, pp. 99-110, 2004.

[41] V. Y. H. Yu and P. M. Dunn, "Development of regionalized perinatal care," Seminars in Neonatology, vol. 9, no. 2, pp. 89-97, 2004.

[42] D. L. Levy, K. Noelke, and J. P. Goldsmith, "Maternal and infant transport program in Louisiana," Obstetrics \& Gynecology, vol. 57, no. 4, pp. 500-504, 1981.

[43] American Academy of Pediatrics and Committee on Fetus and Newborn, "Policy statement, levels of neonatal care," Pediatrics, vol. 114, no. 5, pp. 1341-1347, 2004.

[44] Croatian Society for Perinatal Medicine and Working Group for Perinatal Health Care, "Proposal of organization of perinatal care in the Republic of Croatia," Gynaecologia et Perinatologia, vol. 12, pp. 87-99, 2003.

[45] G. Lewis, "Reviewing maternal deaths to make pregnancy safer," Best Practice and Research: Clinical Obstetrics and Gynaecology, vol. 22, no. 3, pp. 447-463, 2008.

[46] D. Karimian-Teherani, G. Haidinger, T. Waldhoer, A. Beck, and C. Vutuc, "Under-reporting of direct and indirect obstetrical deaths in Austria, 1980-98," Acta Obstetricia et Gynecologica Scandinavica, vol. 81, no. 4, pp. 323-327, 2002.

[47] S. Alexander, K. Wildman, W. Zhang, M. Langer, C. Vutuc, and G. Lindmark, "Maternal health outcomes in Europe," European Journal of Obstetrics Gynecology and Reproductive Biology, vol. 111, supplement 1, pp. S78-S87, 2003.

[48] A. Dražančić, "Maternal mortality," Gynaecologia et Perinatologia, vol. 14, no. 1, pp. 7-17, 2005.

[49] C. McCourt, J. Weaver, H. Statham, S. Beake, J. Gamble, and D. K. Creedy, "Elective cesarean section and decision making: a critical review of the literature," Birth, vol. 34, no. 1, pp. 65-79, 2007.

[50] American College of Obstetricians and Gynecologists and Society for Maternal-Fetal Medicine, "Safe prevention of primary cesarean delivery," Obstetric-Care-Consensus 1, 2014, http://www.acog.org/Resources-And-Publications/ObstetricCare-Consensus-Series/Safe-Prevention-of-the-Primary-Cesarean-Delivery. 


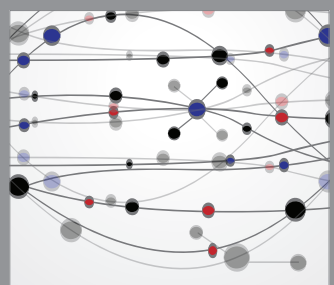

The Scientific World Journal
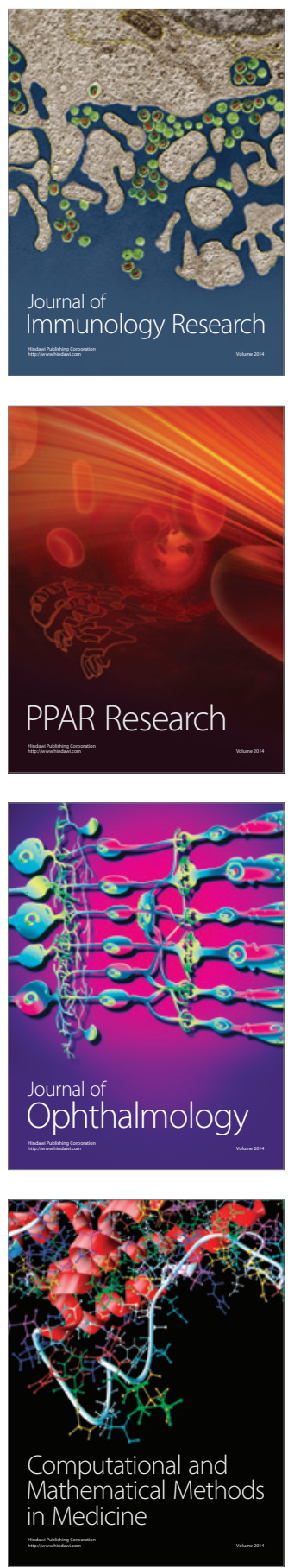

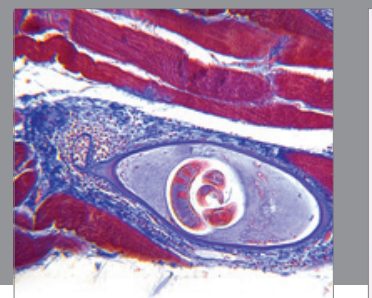

Gastroenterology

Research and Practice
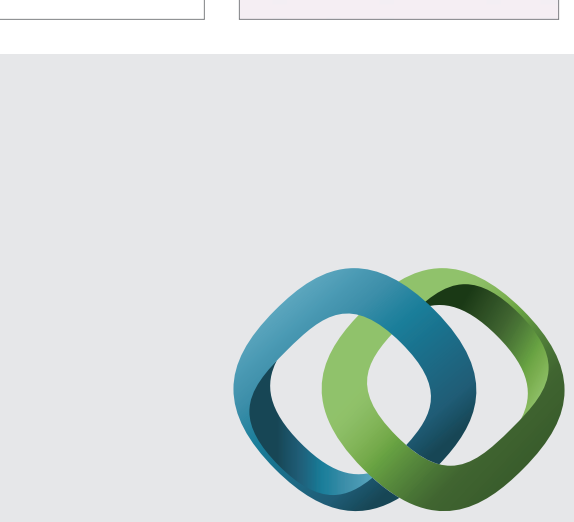

\section{Hindawi}

Submit your manuscripts at

http://www.hindawi.com
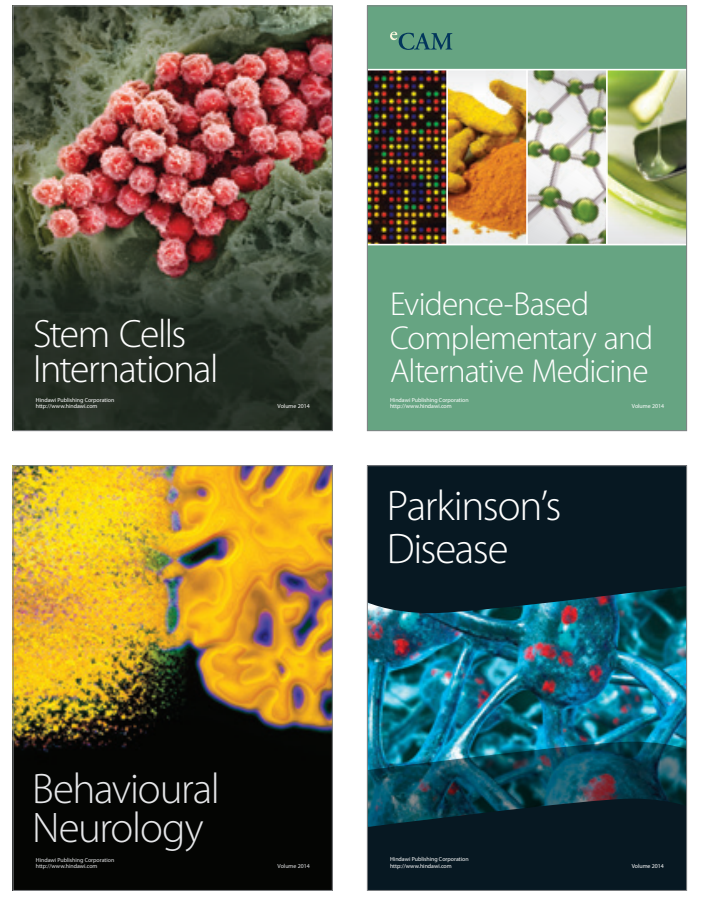
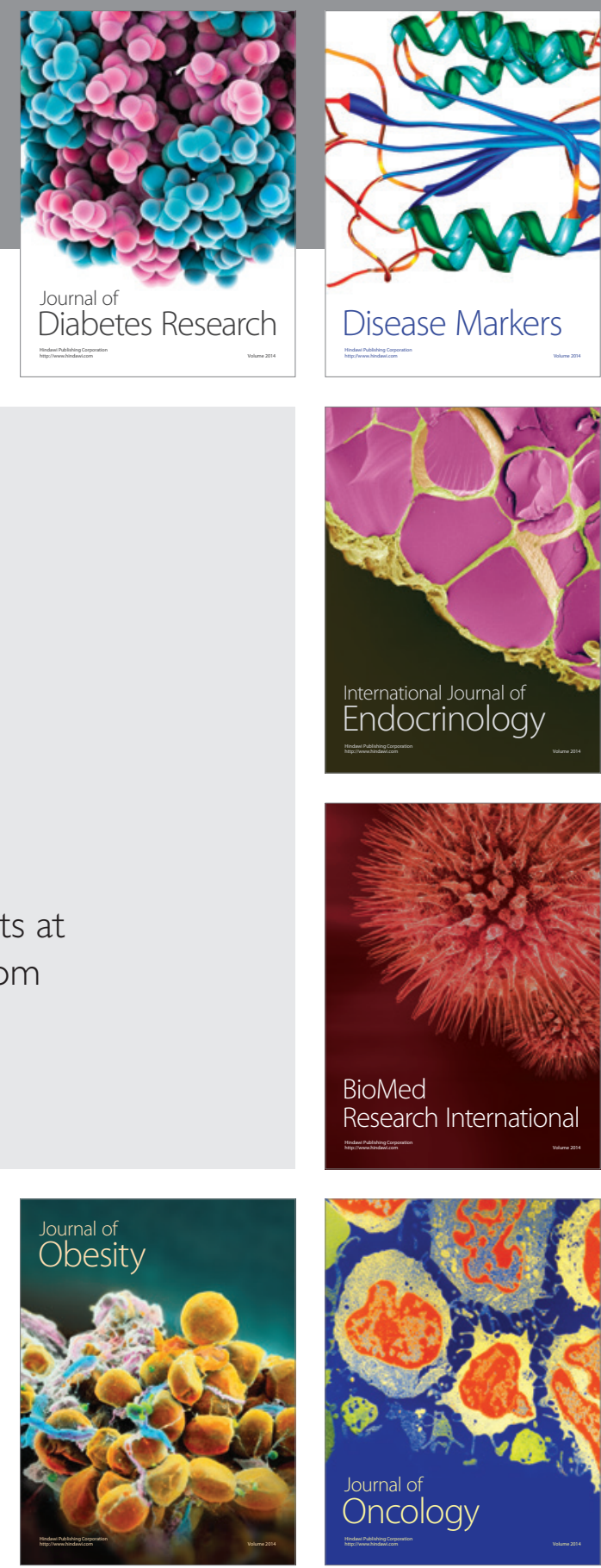

Disease Markers
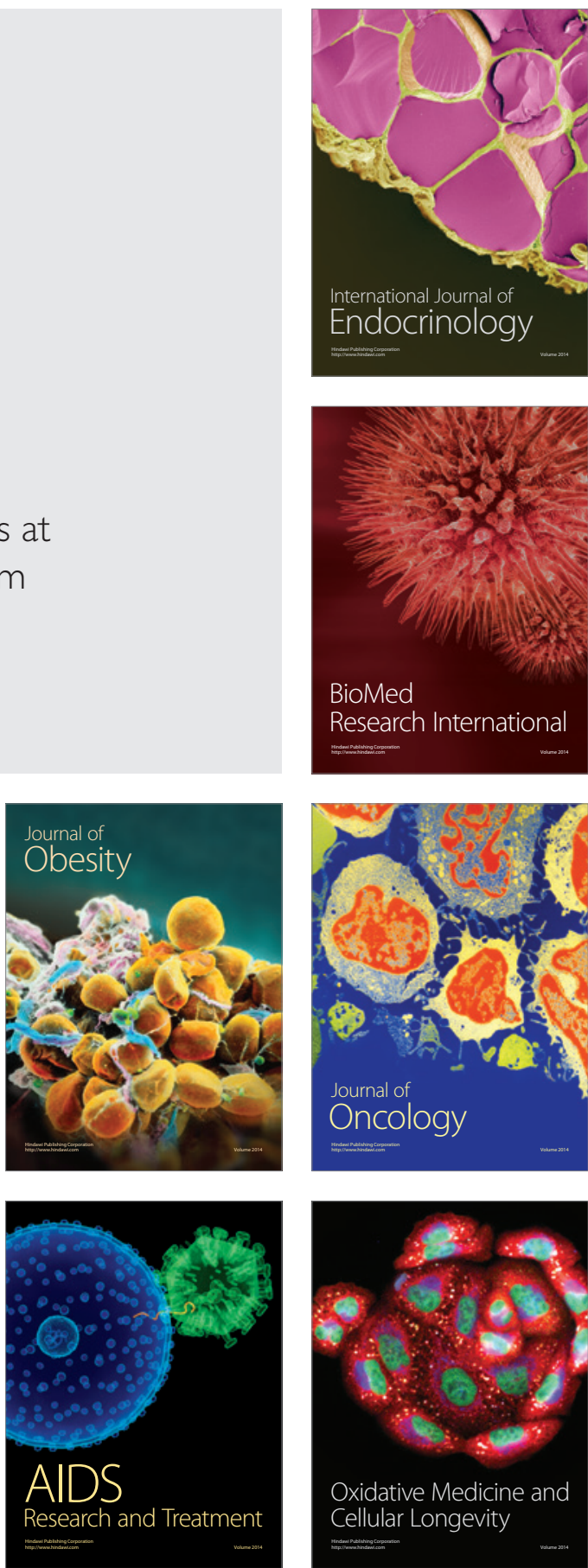